\title{
Major Predisposing Factors to Utilization of Traditional Birth Attendants by Expectant Mothers in Mombasa County, Kenya
}

\author{
Article by Johnson S. Manyiwa ${ }^{1}$, Oso W. Yuko ${ }^{2}$, Bob O. Opiyo ${ }^{3}$ \\ ${ }^{1}$ Public Health Department-Mombasa County Kenya \\ ${ }^{2}$ Amoud University \\ ${ }^{3}$ Technical University of Mombasa \\ E-mail: johnstoneshume@gmail.com
}

\begin{abstract}
The role of Traditional Birth Attendants (TBAs) in improving maternal health has been heavily debated, especially in the focus on Millennium Development Goal (MDG) 5. The use of TBAs is still high in Kenya; TBAs attend to $28 \%$ of all births, relatives attend to $21 \%$ of births, and $7 \%$ give birth without any assistance. Up to $90 \%$ of these maternal and infant deaths are caused by obstetric complications that are preventable. Understanding the factors that contributes to high utilization of TBAs among Kenyan in spite of the free maternity being offered is very important. Hence, this study aimed at determining and ascertaining the critical predisposing factors to utilization of TBAs by expectant mothers in Mombasa County, Kenya. The study adopted a survey research design and was conducted among expectant mothers using semi-structured questionnaire and interview guide. Data was collected from June to September, 2017. Multinomial logistic regression analyses were used to identify factors associated with utilization of TBAs by expectant mothers. Data was analysed using $R$ (version 3.4.3). The study recruited 370 (96.4\%) out of the expected 384 respondents. Various factors such as TBAs live among the community, poverty, culture, facilities being far, fear of harassment by nurses, number of children delivered. To improve the utilization of Skilled Birth Attendants (SBA) services, our finding suggests implementation of strategies like need to improve infrastructure and adequate maternal health services, also improving the staffing and motivation levels for health personnel
\end{abstract}

Keywords: Predisposing factors, Traditional Attendants, Skilled Attendants, Maternal Health, Mombasa County.

\section{Introduction}

The Traditional Birth Attendants (TBAs) are integral members of their communities and provide an important window to local customs, traditions, and perceptions regarding childbirth and new-born care. They provide the majority of primary maternity care in many developing countries, and may function within specific communities in developed countries. They also provide basic health care, support and advice during and after pregnancy and childbirth, based primarily on experience and knowledge acquired informally through the traditions and practices of the communities where they originated (AMREF, 2015). As WHO (1992) observes, Traditional Birth Attendants (TBAs) can potentially improve maternal and new-borns health at community level.

TBAs usually work in rural, remote and other medically underserved areas. Most of them are usually older and respected women in their communities, and they customarily provide essential social support to women during childbirth and also perform cultural rituals. TBAs consider themselves as private health care practitioners who respond to requests for service, to assist women during delivery and immediately post-partum (Bergström \& Goodburn, 2001). Many are highly experienced in a well woman care, including how to recognize and respond appropriately to complications of pregnancy (Bergström \& Goodburn, 2001). AMREF (2015) has now began to increasingly recognized TBAs, since they may have a role to play in improving health outcomes in developing countries because of their access to communities and the relationships they share with women in local communities. However, while the role of TBAs in caring for expectant mothers and conducting deliveries is acknowledged, they are generally not trained to deal with maternal 
complications (Keri et al., 2010). This is where their problem begins, since they may not have received any formal education and training in health care provision, and there are also no specific professional requisites to them such as certification or licensure (Bourbonnais, 2013). As Dietsch (2010) observes, they often learn their trade through apprenticeship or are self-taught. In many communities one of the criteria for being accepted as a TBA by clients is experience as a mother. Many may or may not be integrated in the formal health systems, but they often serve as a bridge between the community and the formal health system, and may accompany women to health facilities for delivery (Fotso et al., 2009). Ikamari and colleagues (2013) pointed out that due to the lack of education, the way many attends to the delivery is risky for women and their babies, and often lead to poor health outcomes and even death.

Throughout history, Traditional Birth Attendants (TBAs) have been the main human resource for women during childbirth. Their role varies across cultures and times, but even today in the era of modernity, they attend the majority of deliveries in rural areas of developing countries (Mannah et al., 2014). According to Kenya demographic health survey of 2012 it's estimated that about $43.1 \%$ of births in Kenya are delivered under the supervision of skilled birth attendant, TBA continues to assist $28 \%$ of the births, $22 \%$ are home deliveries assisted by friends and relatives while $7 \%$ of expectant mothers deliver without assistance. Currently, most published studies investigating reasons for home delivery in developing countries have focused on the structural barriers to facility delivery services such as lack of geographical access to emergency obstetric care and financial limitations. Factors that motivate women to give birth at home and their reasons to seek the assistance of TBAs have not been explored in depth. Hence, this study aimed at exploring the major predisposing factors that still leads to utilization of traditional birth attendants by expectant mothers in Mombasa County, even after the introduction of free maternal services in all public health facilities.

\section{Methods}

\section{Area of study}

The survey was conducted in Mombasa County, which is situated in the South Eastern part of the former Coast Province. Mombasa County is one of the 47 Counties of Kenya and it has a population of 939,370 (KNBS, 2009), with majority of her people living in urban areas. It consists of six subcounties and it is the smallest county in Kenya, covering an area of $229.7 \mathrm{~km}^{2}$ excluding $65 \mathrm{~km}^{2}$ of water mass. It borders Kilifi County to the North, Kwale County to the South, Taita Taveta to the West and the Indian Ocean to the East.

\section{Study population}

The study population comprised of 301,505 women of childbearing age (15-49) in Mombasa County (Government of Kenya, Projected 2016). The study included only expectant women who gave consent to participate in the study voluntarily and were resident of Mombasa County.

\section{Size of the study and sampling}

The number of study participants was calculated using the formula of Fishers et al (1998); n = $\mathrm{Z}^{2} \mathrm{pq} / \mathrm{d}^{2}$. Where $\mathrm{n}=$ sample size for a population; $\mathrm{Z}=\mathrm{z}$-value corresponding to a $95 \%$ level of significance $=1.96 ; \mathrm{p}=$ expected proportion of population of women in Mombasa County $=0.5 ; \mathrm{q}=$ $(1-\mathrm{p})=(1-0.5)=0.5 ;$ and $\mathrm{d}=$ absolute precision, set at $5 \%$.

Therefore,

$$
\frac{1.96^{2 *} * .5 * 0.5}{0.05^{2}}=384 \text { pregnant women }
$$

Stratified random sampling and simple random sampling techniques was used to select the individual members of the sample. Stratified sampling technique was used to determine the proportion of women in each sub county to be included in the sample. Six strata corresponding to the six subcounties (Table 1) were identified. Simple random was used to select the individual members of each stratum for the sample. 
Table 1. Stratified Sampling

\begin{tabular}{|l|l|l|}
\hline Sub-County & Approximate & Number \\
\hline Kisauni & $48680 / 301,505 \times 384$ & 62 \\
\hline Mvita & $73020 / 301,505 \times 384$ & 93 \\
\hline Nyali & $51821 / 301,505 \times 384$ & 66 \\
\hline Likoni & $45540 / 301,505 \times 384$ & 58 \\
\hline Jomvu & $41100 / 301,505 \times 384$ & 52 \\
\hline Changamwe & $41614 / 301,505 \times 384$ & 53 \\
\hline Total & & $\mathbf{3 8 4}$ \\
\hline
\end{tabular}

\section{Data collection}

The data was collected from June, 2017 to September, 2017. Data were collected using a semi structured interviewer-administered questionnaire. Trained enumerators were responsible for collecting the data. The survey was in English; however, the enumerators were capable of translating questions into Kiswahili and the local language, when necessary.

\section{Data management}

The principle researcher entered the data in EpiData database, and then exported to $\mathrm{R}$ statistical package (Version 3.4.3) for analysis. Frequency distributions and percentage were generated for all the variables. For bivariate analysis, chi-square tests were used to measure the significance of relationships between the outcome variable and the predictor variables.

Multicollinearity of the independent variables was assessed. Results that were statistically significant with $\mathrm{p}$-values, $\mathrm{p}<0.05$ were included into the multivariable logistic regression model. Adjusted odds ratio (AOR) and their $95 \%$ confidence intervals were calculated. A p-value less than 0.05 were considered significant.

\section{Ethical approval}

Ethical approval was obtained from the Mombasa County Research Ethical Review Board. The respondents were served with and introductory letter from the researcher that explained the purpose of the study and sought their permission to participate in the study. The study protected the privacy of the respondents and the confidentiality of the information provided by the respondents. Any information collected was not passed to third parties in any form whatsoever without express permission of the source.

\section{Results}

\section{Response rate}

A total of 370 women seeking maternal health services within Mombasa County were interviewed out of a target of 384 respondents representing $96.4 \%$ response rate. The others 14 (3.6\%) refused to consent for the study.

\section{Background characteristics of respondents}

As shown in Table 2, regarding to the socio demographics of the respondents, the study established that, majority of the respondents $133(35.9 \%)$ and $131(35.4 \%)$ had primary education and no formal education respectively while $89(24.1 \%)$ and $17(4.6 \%)$ had secondary and tertiary educations respectively. 71 (19.2\%) of the study participants were not involved any relationship, 9 (2.4\%) had lost their spouse through death while more than three-quarters $(78.4 \%)$ were married; slightly more than half (56.2\%) were married under Traditional beliefs, while $28.1 \%$ and $15.7 \%$ were married under Christian and Islamic faiths respectively. Most of the respondents had delivered 2 or 3 children, each constituting to $29.2 \%$ of the respondents. Moreover, majority (80\%) of the respondents reported that their delivered children were alive. 
DOI: $10.21522 / \mathrm{TIJPH} .2013 .06 .03 . A r t 016$

ISSN: $2520-3134$

Table 2: Sociodemographic data of the respondents

\begin{tabular}{|l|l|l|}
\hline Variables & $\begin{array}{l}\text { No of Respondents } \\
\text { (n) }\end{array}$ & Proportion (\%) \\
\hline a). Education background (n=370) & & \\
No Education & 131 & 35.4 \\
Primary & 133 & 35.9 \\
Secondary & 89 & 24.1 \\
Tertiary & 17 & 4.6 \\
\hline b). Marital status (n=370) & & \\
Single & 71 & 19.2 \\
Married & 290 & 78.4 \\
Widow & 9 & 2.4 \\
\hline c). Nature of married (n=299) & & \\
Chraditional & 168 & 56.2 \\
Muslim & 84 & 28.1 \\
\hline d). Number of children delivered & 47 & 15.7 \\
(n=370) & 46 & \\
1 & 108 & 12.4 \\
2 & 108 & 29.2 \\
3 & 54 & 29.2 \\
4 & 27 & 14.6 \\
5 & 18 & 7.3 \\
6 & 8 & 4.9 \\
7 & 1 & 2.2 \\
8 & & 0.2 \\
\hline e). All children delivered are alive & & \\
(n=370) & 296 & 80 \\
Yes & 74 & \\
No & & \\
\hline
\end{tabular}

\section{Respondents' knowledge on traditional birth attendants (TBAs) and their services}

As shown in Table 3, almost all of the respondents (98.4\%) were aware of traditional birth attendants (TBAs) in their areas, while only a few [6(1.6\%)] were not aware. Of those who were aware of the TBAs in their area, slightly above half $(51.9 \%)$ revealed that the traditional birth attendants (TBAs) were their neighbours, whereas $87(23.9 \%)$ of the respondents indicated that the traditional birth attendants (TBAs) were their friends. Further, 37(10.2\%) and 28(7.7\%) of the respondents indicated that the traditional birth attendants (TBAs) were there aunts' and grandmothers' respectively, while $11(3 \%), 10(2.7 \%)$ and $2(0.5 \%)$ of the respondents reported that the traditional birth attendants (TBAs) were their cousins', mothers' and other relatives' respectively.

On the questions on whether the traditional birth attendants (TBAs) were useful members of the society, majority of the respondents indicated that they were very useful members of the community $320(87.9 \%)$ with $16(4.4 \%)$ of them indicating that they were readily available as they reside with them within the community. The other $15(4.1 \%)$ indicated that traditional birth attendants (TBAs) were not useful, with $13(3.6 \%)$ of them feeling that they were mostly important in the rural. Majority [338(92.9\%)] of the respondents who were aware of TBAs in their area were also aware of other mothers who had been assisted by the traditional birth attendants (TBAs) while 26(7.1\%) were not aware of other mothers who had been assisted by the traditional birth attendants (TBAs). On the other hand, $325(89.3 \%)$ of the mothers who had sought the services of traditional birth attendants (TBAs) previously reported having a good experience while 39(10.7\%) reported bad experience. 
Table 3. Knowledge concerning traditional birth attendants (TBAs) and their services

\begin{tabular}{|c|c|c|}
\hline Variable & No of Respondents (n) & Proportion (\%) \\
\hline $\begin{array}{l}\text { a). Know TBAs in their area } \\
(\mathbf{n}=370) \\
\text { Yes } \\
\text { No }\end{array}$ & $\begin{array}{l}364 \\
6\end{array}$ & $\begin{array}{l}(98.4) \\
(1.6)\end{array}$ \\
\hline $\begin{array}{l}\text { b). Relationship with TBAs }(\mathbf{n}=\mathbf{3 6 4}) \\
\text { Neighbour } \\
\text { Friends } \\
\text { Aunt } \\
\text { Grandmother } \\
\text { Cousin } \\
\text { Mother } \\
\text { Relative }\end{array}$ & $\begin{array}{l}189 \\
87 \\
37 \\
28 \\
11 \\
10 \\
2\end{array}$ & $\begin{array}{l}(51.9) \\
(23.9) \\
(10.2) \\
(7.7) \\
(3) \\
(2.7) \\
(0.5)\end{array}$ \\
\hline $\begin{array}{l}\text { c). Your view on the usefulness of } \\
\text { TBAs (n=364) } \\
\text { Very useful } \\
\text { Are readily available and resides } \\
\text { within the community } \\
\text { Not very much useful } \\
\text { Mostly important in the rural }\end{array}$ & $\begin{array}{l}320 \\
16 \\
15 \\
13\end{array}$ & $\begin{array}{l}(87.9) \\
(4.4) \\
(4.1) \\
(3.6)\end{array}$ \\
\hline $\begin{array}{l}\text { d). Aware of other mothers who } \\
\text { have been assisted by TBAs }(n=364) \\
\text { Yes } \\
\text { No }\end{array}$ & $\begin{array}{l}338 \\
26\end{array}$ & $\begin{array}{l}(92.9) \\
(7.1)\end{array}$ \\
\hline $\begin{array}{l}\text { e). Experiences of the other mothers } \\
\text { who have been assisted by TBAs } \\
\text { (n=364) } \\
\text { Good } \\
\text { Not good }\end{array}$ & $\begin{array}{l}325 \\
39\end{array}$ & $\begin{array}{l}(89.3) \\
(10.7)\end{array}$ \\
\hline
\end{tabular}

\section{Respondents' preference for the utilization of traditional birth attendant services}

As presented in Table 4 and Figure 1, when the respondents were asked the reasons why they had preferred services of traditional birth attendance, $43.8 \%$ cited that TBAs live among in the community, $29.5 \%$ indicated that poverty was the reason why they sought out services of traditional birth attendants (TBAs), culture, health facilities being far and fear of being harassed by nurses were some of the other factors that made them to opt for traditional birth attendants (TBAs) services. 7.3\% indicated that they preferred traditional birth attendants (TBAs) services since they were closer to their families while giving birth. Further, $6.8 \%$ of the respondents indicated that they were using the traditional birth attendants (TBAs) services since TBAs charges less and the amount can be paid in instalments. Negative attitudes towards male nurses, fear of being watched by strangers, language barrier and lack of maternal education constituted $5.9 \%, 3.2 \%, 1.9 \%$ and $1.6 \%$ respectively of some of the reasons why respondents preferred TBAs services. 
DOI: $10.21522 /$ TIJPH.2013.06.03.Art016

ISSN: $2520-3134$

Table 4. Factors contributing to respondents' use of traditional birth attendant services

\begin{tabular}{|l|l|l|}
\hline Characteristics & $\begin{array}{l}\text { No of } \\
\text { Respondents (n) }\end{array}$ & $\begin{array}{l}\text { Proportion } \\
\text { (\%) }\end{array}$ \\
\hline $\begin{array}{l}\text { Reasons for preference of TBA services (n=370) } \\
\text { TBAs nearer and live among the community }\end{array}$ & 162 & $(43.8)$ \\
Poverty, culture, health facilities far, fear of harassment & 109 & $(29.5)$ \\
by nurses & 27 & $(7.3)$ \\
Being closer to family members when giving birth & 25 & $(6.8)$ \\
TBAs charges less and the amount can be paid slowly & 22 & $(5.9)$ \\
Negative attitudes towards male nurses & 12 & $(3.2)$ \\
Fear of being watched by strangers & 7 & $(1.9)$ \\
Language barrier & 6 & $(1.6)$ \\
Lack of maternal education & & \\
\hline
\end{tabular}

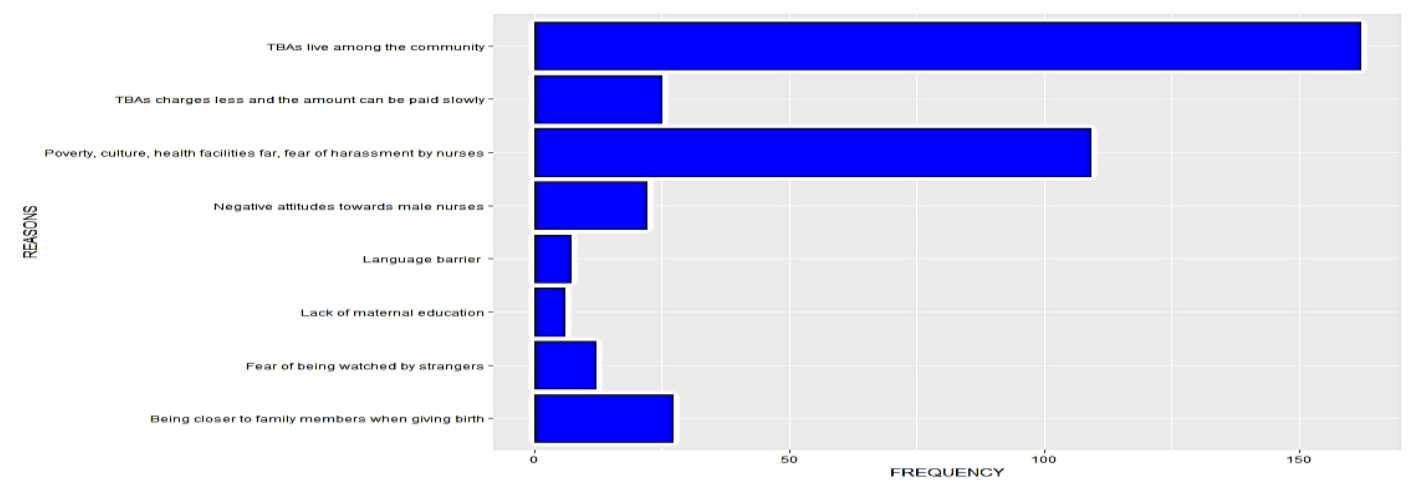

Figure 1. Reasons for preference of TBA services

\section{Association between socio-demographics and respondents' place of delivery}

As shown in Table 5, respondents who had primary education 114(85.7\%) and those who had no education 112(85.5\%) had higher proportion of delivering their babies at home/outside hospital and the differences were significant $\left(\mathrm{chi}=64.462, \mathrm{p}=6.54 \mathrm{e}^{-14}\right.$ ). Further, when the findings of this study were subjected to logistic regression analysis, it showed that having tertiary education increased the odds of delivering at home/outside hospital by $14.4(\mathrm{OR}=14.4$ [95\% $\mathrm{CI}=4.56-45.51])$ as compared to those who had primary education. Similarly, as compared to those who had primary education, those who had secondary and no education at all had odds of delivering at home/outside hospital by 6.14 $(\mathrm{OR}=6.14$ [95\% CI=3.24-11.63]) and $1.02(\mathrm{OR}=1.02$ [95\% $\mathrm{CI}=0.51-2.02])$ respectively.

With regards to marital status, the proportion of single mothers, married mothers and widow mothers who had deliver their babies at home/outside hospital was $74.6 \%, 72.7 \%$ and $44.4 \%$ respectively. This difference in proportion though was not statistically significant (chi=4.3238, $\mathrm{p}=0.1151$ ). Further logistic regression analysis showed that being a single woman increases the odds of delivering at home/outside hospital by $1.03(\mathrm{OR}=1.03$ [95\% $\mathrm{CI}=0.57-1.87])$ as compared to a married woman.

Expectant mothers married under Traditional practise had significantly higher proportion $(88.1 \%)$ of delivering their babies at home/outside hospital compared to other categories of form of marriage. This differences in proportions between nature of married and place of delivery was significant (chi=38.821, $\left.\mathrm{p}=3.72 \mathrm{e}^{-09}\right)$.

Similarly, expectant mothers who had given birth to four children had a high proportion $(98.1 \%)$ of delivering their babies at home/outside hospital compared to the expectant mothers who had given 
birth to less than or more than four children. This differences too in proportions between number of children delivered and place of delivery was also significant $\left(\operatorname{chi}=113.66, \mathrm{p}=<2.2 \mathrm{e}^{-16}\right)$.

Expectant mothers who reported to have not loss a child after birth recorded a higher proportion $66(89.2 \%)$ of delivering their babies at home/outside hospital as compared to those whose children were alive after birth. This differences in proportions too was significant (chi=9.759, $\mathrm{p}=0.0018$ ). Further logistic regression analysis showed that those who had not lost their children after delivery had the odds of delivering at home/outside hospital by $71 \%$ (OR=0.29 [95\% CI=0.13-0.63]) as compared to those whose children were alive after birth.

Therefore, education background $\left(P=6.54 \mathrm{e}^{-14}\right)$, nature of married $\left(P=3.72 \mathrm{e}^{-09}\right)$, number of children delivered $\left(P=<2.2 \mathrm{e}^{-16}\right)$ and children being alive $(P=0.0018)$ were significantly related with the use of traditional birth attendant services since their $p$ value $>\alpha=0.05$, thus null hypothesis $\left(\mathrm{H}_{0}\right)$ was rejected and alternative hypothesis $\left(\mathrm{H}_{1}\right)$ accepted. This meant that education background, nature of married, number of children delivered and children being alive were some of the critical predisposing factors that lead to utilization of traditional birth attendants by expectant mothers in Mombasa County, Kenya

Table 5. Association between socio-demographics and respondents' place of delivery

\begin{tabular}{|c|c|c|c|c|}
\hline \multirow{2}{*}{ Variables } & \multicolumn{4}{|l|}{ Place of delivery } \\
\hline & $\begin{array}{l}\text { Have delivered } \\
\text { at one time at } \\
\text { home/outside } \\
\text { health facility }\end{array}$ & $\begin{array}{l}\text { Never delivered } \\
\text { at one time at } \\
\text { home/outside } \\
\text { health facility }\end{array}$ & $\begin{array}{l}\text { Crude Odds Ratio } \\
(95 \% \text { CI) p-value }\end{array}$ & $\begin{array}{l}\text { Chi-square, } \\
\text { p-value }\end{array}$ \\
\hline $\begin{array}{l}\text { a). Education } \\
\text { background }(\mathbf{n = 3 7 0}) \\
\text { No Education } \\
\text { Primary } \\
\text { Secondary } \\
\text { Tertiary }\end{array}$ & $\begin{array}{l}112(85.5 \%) \\
114(85.7 \%) \\
44(49.4 \%) \\
5(29.4 \%)\end{array}$ & $\begin{array}{l}19(14.5 \%) \\
19(14.3 \%) \\
45(51.6 \%) \\
12(70.6 \%)\end{array}$ & $\begin{array}{l}1.02[0.51-2.02] 1 \\
\text { Reference } \\
6.14[3.24-11.63] \\
1.22 \mathrm{e}^{-08} \\
14.4[4.56-45.51] \\
3.77 \mathrm{e}^{-07}\end{array}$ & $\begin{array}{l}\text { Chi-square= } \\
64.462 \\
\text { p-value= } \\
\mathbf{6 . 5 4 e}^{-14 *}\end{array}$ \\
\hline $\begin{array}{l}\text { b). Marital status } \\
(\mathbf{n}=\mathbf{3 7 0}) \\
\text { Single } \\
\text { Married } \\
\text { Widow }\end{array}$ & $\begin{array}{l}53(74.6 \%) \\
218(72.7 \%) \\
4(44.4 \%)\end{array}$ & $\begin{array}{l}18(25.4 \%) \\
72(17.3 \%) \\
5(55.6 \%)\end{array}$ & $\begin{array}{l}1.03[0.57- \\
1.87] 0.36 \\
\text { Reference } \\
3.78[1.0- \\
14.48] 0.03\end{array}$ & $\begin{array}{l}\text { Chi-square= } \\
4.3238 \\
\text { p-value }= \\
0.1151\end{array}$ \\
\hline $\begin{array}{l}\text { c). Nature of married } \\
(\mathbf{n}=\mathbf{2 9 9}) \\
\text { Traditional } \\
\text { Christian } \\
\text { Muslim }\end{array}$ & $\begin{array}{l}148(88.1 \%) \\
46(54.8 \%) \\
28(59.6 \%)\end{array}$ & $\begin{array}{l}20(11.9 \%) \\
38(45.2 \%) \\
19(41.4 \%)\end{array}$ & $\begin{array}{l}\text { Reference } \\
6.11[3.24-11.53] \\
8.06 \mathrm{e}^{-09} \\
5.02[2.38-10.59] \\
1.94 \mathrm{e}^{-05} \\
\end{array}$ & $\begin{array}{l}\text { Chi-square= } \\
38.821 \\
\text { p-value }= \\
\text { 3.72e }^{-09 *}\end{array}$ \\
\hline $\begin{array}{l}\text { d). Number of children } \\
\text { delivered }(\mathbf{n}=\mathbf{3 7 0}) \\
1 \\
2 \\
3 \\
4 \\
5 \\
6 \\
7 \\
8\end{array}$ & $\begin{array}{l}8(17.4 \%) \\
74(68.5 \%) \\
97(89.8 \%) \\
53(98.1 \%) \\
24(88.9 \%) \\
13(72.2 \%) \\
5(62.5 \%) \\
1(100 \%)\end{array}$ & $\begin{array}{l}38(82.6 \%) \\
34(31.5 \%) \\
11(10.2 \%) \\
1(1.9 \%) \\
3(10.1 \%) \\
5(27.8 \%) \\
3(37.5 \%) \\
0\end{array}$ & $\begin{array}{l}41.9[15.64-112.2] \\
<2.2 \mathrm{e}^{-16} \\
4.05[1.93-8.53] \\
0.0002 \\
\text { Reference } \\
0.17[0.02- \\
1.32] 0.11 \\
1.1[0.29-4.26] 1 \\
3.39[1.02- \\
11.32] 0.09\end{array}$ & 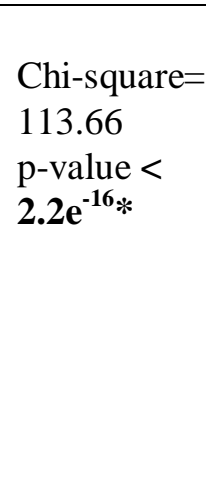 \\
\hline
\end{tabular}


DOI: $10.21522 /$ TIJPH.2013.06.03.Art016

ISSN: $2520-3134$

\begin{tabular}{|c|c|c|c|c|}
\hline & & & $\begin{array}{l}5.29[1.11- \\
25.21] 0.08 \\
0\end{array}$ & \\
\hline $\begin{array}{l}\text { e). All children } \\
\text { delivered are alive } \\
(\mathbf{n}=370) \\
\text { Yes } \\
\text { No }\end{array}$ & $\begin{array}{l}209(70.6 \%) \\
66(89.2 \%)\end{array}$ & $\begin{array}{l}87(29.4 \%) \\
8(10.8 \%)\end{array}$ & $\begin{array}{l}\text { Reference } \\
0.29[0.13- \\
0.63] 0.002\end{array}$ & $\begin{array}{l}\text { Chi-square= } \\
9.759 \\
\text { p-value }= \\
\text { 0.0018* }\end{array}$ \\
\hline
\end{tabular}

\section{Association between respondents' knowledge of traditional birth attendant and the place of delivery}

As shown in Table 6, these study's respondents who knew the Traditional birth attendants (TBAs) in their areas had a higher proportion 275(75.5\%) of home/outside hospital delivery than those who were not aware of any Traditional birth attendants (TBAs) in their area. This difference in proportion was significant (chi=13.92, $\mathrm{p}=0.0002$ ).

On their relationship with the Traditional birth attendants (TBAs), those who responded that the Traditional birth attendants (TBAs) were their grandmother, cousin, mother and relative had a higher proportion $(100 \%)$ of home/outside hospital delivery than the other forms of relationships. This difference in proportion too was significant $\left(\mathrm{chi}=35.89, \mathrm{p}=2.90 \mathrm{e}^{-06}\right)$.

The respondents who stated that the Traditional birth attendants (TBAs) were very useful since they were readily available had a higher turn-out 16(100\%) of home/outside hospital delivery compared to those with different view and this difference in proportion too was significant $\left(\mathrm{chi}=45.802, \mathrm{p}=6.25 \mathrm{e}^{-10}\right)$. Further logistic regression analysis showed that those who responded that the Traditional birth attendants (TBAs) were not very useful had the odds of delivering at home/outside hospital increased by $4.16(\mathrm{OR}=4.16$ [95\% $\mathrm{CI}=1.46-11.87])$ while those who responded that the Traditional birth attendants (TBAs) were only useful in the rural had the odds of delivering at home/outside hospital increased by 43.7 (OR=43.7 [95\% CI=5.6-341.6]).

The expectant mothers who were aware of other mothers who had delivered with the Traditional birth attendants (TBAs) assistance, had a higher proportion (81.4\%) of home/outside hospital delivery compared to those who were not aware of other mothers who had delivered with the Traditional birth attendants (TBAs) assistance. The difference in proportion was observed to be statistically significant too $\left(\mathrm{chi}=82.17, \mathrm{p}=<2.2 \mathrm{e}^{-16}\right)$.

Moreover, the expectant mothers who stated that the other mothers had a good experience from the services offered by the Traditional birth attendants (TBAs), had a high proportion (84.3\%) of home/outside hospital delivery compared to those who reported bad experience under Traditional birth attendants (TBAs) care. The difference in proportion was observed to be statistically significant too $\left(\mathrm{chi}=43.46, \mathrm{p}=4.32 \mathrm{e}^{-11}\right)$.

Therefore, in comparing the respondents' knowledge of traditional birth attendant and the place of delivery as shown in Table 4.8, indicated that one knowing TBAs in their area $(P=0.0002)$, their relationship with TBAs $\left(P=2.90 \mathrm{e}^{-06}\right)$, their view on the usefulness of TBAs $\left(P=6.25 \mathrm{e}^{-10}\right)$, being aware of other mothers who have been assisted by TBAs $\left(P<2.2 \mathrm{e}^{-16}\right)$ and knowing the experiences of the other mothers who have been assisted by TBAs $\left(P=4.32 \mathrm{e}^{-11}\right)$ were significantly related with the use of traditional birth attendant services since their $p$ value $>\alpha=0.05$ (Table 4.8), thus $\mathrm{H}_{0}$ was rejected and $\mathrm{H}_{1}$ accepted. This meant that one knowing TBAs in their area, their relationship with TBAs, their view on the usefulness of TBAs, being aware of other mothers who have been assisted by TBAs and knowing the experiences of the other mothers who have been assisted by TBAs were some of the critical predisposing factors that lead to utilization of traditional birth attendants by expectant mothers in Mombasa County, Kenya. 
Table 6. Association between respondents' knowledge of traditional birth attendant and the place of delivery

\begin{tabular}{|c|c|c|c|c|}
\hline \multirow{2}{*}{ Variable } & \multicolumn{4}{|l|}{ Place of delivery } \\
\hline & $\begin{array}{l}\text { Have delivered } \\
\text { at one time at } \\
\text { home/outside } \\
\text { health facility }\end{array}$ & $\begin{array}{l}\text { Never delivered } \\
\text { at one time at } \\
\text { home/outside } \\
\text { health facility }\end{array}$ & $\begin{array}{l}\text { Crude Odds } \\
\text { Ratio (95\% CI) } \\
\text { p-value }\end{array}$ & $\begin{array}{l}\text { Chi- } \\
\text { square, } \\
\text { p-value }\end{array}$ \\
\hline $\begin{array}{l}\text { a). Know TBAs in their } \\
\text { area }(\mathbf{n}=\mathbf{3 7 0}) \\
\text { Yes } \\
\text { No }\end{array}$ & $\begin{array}{l}275(75.5 \%) \\
0\end{array}$ & $\begin{array}{l}89(24.5 \%) \\
6(100 \%)\end{array}$ & $\begin{array}{l}\text { Reference } \\
0\end{array}$ & $\begin{array}{l}\text { Chi-square } \\
=13.92 \\
\text { p-value }= \\
\mathbf{0 . 0 0 0 2}\end{array}$ \\
\hline $\begin{array}{l}\text { b). Relationship with } \\
\text { TBAs }(\mathbf{n}=364) \\
\text { Neighbour } \\
\text { Friends } \\
\text { Aunt } \\
\text { Grandmother } \\
\text { Cousin } \\
\text { Mother } \\
\text { Relative }\end{array}$ & $\begin{array}{l}133(70.4 \%) \\
55(63.2 \%) \\
36(97.3 \%) \\
28(100 \%) \\
11(100 \%) \\
10(100 \%) \\
2(100 \%)\end{array}$ & $\begin{array}{l}56(29.6 \%) \\
32(36.8 \%) \\
1(2.7 \%) \\
0 \\
0 \\
0 \\
0\end{array}$ & $\begin{array}{l}\text { Reference } \\
1.4[0.81-2.36] 0.3 \\
0.07[0.01- \\
0.49] 0.001 \\
0 \\
0 \\
0 \\
0 \\
\end{array}$ & $\begin{array}{l}\text { Chi-square } \\
=35.89 \\
\text { p-value }= \\
\mathbf{2 . 9 0 e}^{-06}\end{array}$ \\
\hline $\begin{array}{l}\text { c). Your view on the } \\
\text { usefulness of TBAs } \\
\text { (n=364) } \\
\text { Very useful } \\
\text { Are readily available and } \\
\text { resides within the } \\
\text { community } \\
\text { Not very much useful } \\
\text { Mostly important in the } \\
\text { rural }\end{array}$ & $\begin{array}{l}251(78.4 \%) \\
16(100 \%) \\
7(46.7 \%) \\
1(7.7 \%)\end{array}$ & $\begin{array}{l}69(21.6 \%) \\
0 \\
8(53.3 \%) \\
12(92.3 \%)\end{array}$ & $\begin{array}{l}\text { Reference } \\
0 \\
4.16[1.46- \\
11.87] 0.01 \\
43.7[5.6- \\
341.6] 3.8 \mathrm{e}^{-08}\end{array}$ & $\begin{array}{l}\text { Chi-square } \\
=45.802 \\
\text { p-value }= \\
\mathbf{6 . 2 5}^{-10}\end{array}$ \\
\hline $\begin{array}{l}\text { d). Aware of other } \\
\text { mothers who have been } \\
\text { assisted by TBAs } \\
(\mathbf{n = 3 6 4 )} \\
\text { Yes } \\
\text { No }\end{array}$ & $\begin{array}{l}275(81.4 \%) \\
0\end{array}$ & $\begin{array}{l}63(18.6 \%) \\
26(100 \%)\end{array}$ & $\begin{array}{l}\text { Reference } \\
0\end{array}$ & $\begin{array}{l}\text { Chi-square } \\
=82.17 \\
\text { p-value } \\
<2.2 \mathrm{e}^{-16}\end{array}$ \\
\hline $\begin{array}{l}\text { e). Experiences of the } \\
\text { other mothers who have } \\
\text { been assisted by TBAs } \\
\text { (n=338) } \\
\text { Conducted well } \\
\text { Not good }\end{array}$ & $\begin{array}{l}274(84.3 \%) \\
1(7.7 \%)\end{array}$ & $\begin{array}{l}51(15.7 \%) \\
12(92.3 \%)\end{array}$ & $\begin{array}{l}\text { Reference } \\
64.5[8.2-506.7] \\
4.3 \mathrm{e}^{-11}\end{array}$ & $\begin{array}{l}\text { Chi-square } \\
=43.46 \\
\text { p-value }= \\
\mathbf{4 . 3 2}^{-11}\end{array}$ \\
\hline
\end{tabular}

\section{Logistic regression analysis}

As shown in Table 7, a logistic regression analysis of sociodemographic characteristics of respondents and respondents' knowledge of traditional birth attendant and the use of their services revealed that only the number of children delivered (adjusted odds ratio $[\mathrm{aOR}]=2.08,95 \% \mathrm{CI}[1.2-$ 3.46], $P=0.0059$ ), being aware of other mothers who have been assisted by TBAs (aOR $=1.4,95 \%$ CI [0.87-2.13], $P=0.002)$ and knowing the experiences of the other mothers who have been assisted by TBAs $(\mathrm{aOR}=1.69,95 \%$ CI $[1.21-2.451], P=0.0031)$ were significantly related with the use of 
DOI: $10.21522 /$ TIJPH.2013.06.03.Art016

ISSN: $2520-3134$

traditional birth attendant services hence could be used to predicts the utilization of traditional birth attendant services in this study.

Table 7. Independent predictors of traditional birth attendant utilization

\begin{tabular}{|l|l|l|}
\hline Coefficients & $\begin{array}{l}\text { Adjusted Odds Ratio } \\
(\mathbf{9 5} \% \text { CI }\end{array}$ & P-value \\
\hline Education background & $0.716(0.173-11.39)$ & 0.3645 \\
\hline Nature of married & $1.53(1.06-2.25)$ & 0.2237 \\
\hline Number of children delivered & $2.08(1.2-3.46)$ & $\mathbf{0 . 0 0 5 9} *$ \\
\hline All children delivered are alive & $3.98(0.52-5.04)$ & 0.7474 \\
\hline Know TBAs in their area & $1.23(0.83-1.82)$ & 0.9999 \\
\hline Relationship with TBAs & $1.35(0.43-4.47)$ & 0.5637 \\
\hline Your view on the usefulness of TBAs & $2.74(0.0008-14.9)$ & 0.8848 \\
\hline $\begin{array}{l}\text { Aware of other mothers who have } \\
\text { been assisted by TBAs }\end{array}$ & $1.4(0.87-2.13)$ & $\mathbf{0 . 0 0 2} *$ \\
\hline $\begin{array}{l}\text { Experiences of the other mothers who } \\
\text { have been assisted by TBAs }\end{array}$ & $1.69(1.21-2.451)$ & $\mathbf{0 . 0 0 3 1} *$ \\
\hline
\end{tabular}

\section{Discussion}

Traditional birth attendants provide the majority of primary maternity care in many developing countries, and may function within specific communities in developed countries. They provide basic health care, support, advice during and after pregnancy and childbirth, based primarily on experience and knowledge acquired informally through the traditions and practices of the communities where they originated (WHO, 2010).

This study was intended to assess the major predisposing factors that contribute to utilization of traditional birth attendants by expectant mothers in Mombasa County, Kenya. The study findings indicated that a variety of factors were contributing to the utilization of traditional birth attendants by expectant mothers in the study area. In the univariate analysis model, various factors were found to significantly contribute to the utilization of traditional birth attendants among expectant mothers in Mombasa County. Factors such as education background, nature of married, number of children delivered, children delivered being alive, knowing TBAs and having a relationship with TBAs, knowing the usefulness/role of the TBAs, being aware of other mothers who have been assisted by TBAs and knowing the experiences of the other mothers who have been assisted by TBAs were some of the factors that independently contributed to traditional birth attendant's utilization in this model. When these factors were subjected to multivariate regression model, only the number of children one had delivered, being aware of other mothers who have been assisted by TBAs and knowing the experiences of the other mothers who have been assisted by TBAs were significantly associated with the utilization of traditional birth attendants' service in this model. It was also revealed that factors such as health facilities being distantly far, harassment by health staffs (nurses), payment for unavailable items in most of the facilities, TBAs living within the community of the expectant mothers, poverty, culture, negative attitudes towards male nurses, fear of being watched by strangers during delivery, language barrier and lack of maternal education as contributing factors to traditional birth attendant's utilization (TBAs) in this study.

Majority of the study participants who were seeking the services of traditional birth attendants had little or no education at all. This study finding is in agreement with other previous studies conducted in various sites. In studies conducted by Fisher et al (1998), Mwewa and Michelo (2010) reported that educated women tend to give birth to few children and deliver at a health facility compared to women with little or no education. Similarly, this study finding also showed that the nature under which one 
was married also played a significant role in the utilization of traditional birth attendant's services. Women who were married under traditional $(66.7 \%)$ customs tend to utilize more the services of traditional birth attendant compared to those who were married under both Christianity $(20.7 \%)$ and Islamic (12.7\%) customs. Most traditional marriages tend to make people conservative in that people have to maintain their culture, hence such people will hardly accept different ways of doing things; they will prefer home to the health facilities delivery because they are not sure about what happens in the health facilities and they have also to confine to the culture requirement.

Remarkably, it was also observed that mothers who had earlier delivered two to three children and these children were alive were more likely to seek services of traditional birth attendant. Therefore, women's decisions on the place of delivery seem to be influenced by their evaluation of the comparative analysis based on their past experience with either delivery at the health facility or at home. This finding in agreement with Navaneetham and Dharmalingam (2006) who reported that mothers who had previously delivered successfully with no complications tend to deliver at home. Moreover, our findings suggest that most women who had utilized the services of traditional birth attendant had a negative attitude towards the health services provided at the facilities because of their perceived poor quality due to harassment by health staffs, lack of equipment, lack of staffs and payment for unavailable items. Moreover, women perceived various barriers including presence of male nurses in most of the health facilities in the area, being looked by many people when giving birth, low education level to comprehend fully on the usefulness of the utilization of Skilled Birth Attendants (SBAs) and also being forbidden by the husband from seeking SBAs as some of the factors which prevented them from delivering at the health facility. In our opinion, public health interventions focusing on improving maternal health outcomes would benefit from targeting women's perceived susceptibility as an important determinant of their health behaviour change. Public health interventions would also benefit from mitigating physical and economic barriers preventing women from accessing maternal healthcare services offered by variety of health facilities in the country.

The findings of this study also showed that the expectant women reported that they seeking the services of traditional birth attendant because the traditional birth attendants were nearer and live among them in the community (43.8\%), with others also citing poor transport means and insecurity in cases when the labor commences at night. This key finding concurs with what other researchers' observed. Shiferaw et al (2013) reported that most women delivered at home because the labor began suddenly and TBAs were more nearer to them compared to a particular health facility. Thaddeus and Maine (1994) stated that most pregnant women are not able to access transport services when they develop labor mostly due to the poor road network and infrastructure especially in rural and poor urban regions in Africa. Within rural Mombasa County, health facilities are sparsely distributed with very poor road network and erratic public transport system. Most of the women could have developed labor at night when the public means of transport is not available. Interventions such as "waiting homes" near health facilities to accommodate the expectant mothers residing far from the nearest health facilities days before delivery day can be helpful in such scenarios.

Consistent with other previous studies conducted in different sites (Nyamtema et al., 2011, Sialubanje et al.,2014) this study observed that living with the TBAs in the same community, knowing them, and having trust in them were found to be important factors influencing women's attitude towards TBAs. Most women indicated that TBAs had a "more humane" attitude towards mothers during labor than the nurses. Indeed, the nurses, who, could usually not be found at the clinic, shouted at them during delivery. This finding is consistent with previous studies (Stekelenburg et al.,2004, Titaley et al.,2010) which have suggested that public health interventions would benefit from focusing on improving the staffing and motivation levels for midwives and nurses in the clinics, as well as encouraging collaboration with TBAs.

Additionally, culture was another factor that influenced use of the TBAs services by the respondents. The senior or elder member of the community were reported to encourage the younger ones out of experience to go to the TBAs and it would be difficult for them to resist the pressure as it is a long time tradition in the community of using their services. They believe that delivery is a natural rite of passage for women and can be handled by a TBA; therefore, home delivery is preferred except where complications occur. Similar findings were reported by Titaley and colleagues (2010) and 
Vieira and colleagues (2012) who both reported significance of culture and deliveries conducted at home by TBAs. Titaley and colleagues (2010) indicated that, in some cultures, there are certain rituals that follow delivery whereby the home provides a good environment.

The respondents also revealed that they were utilizing the services of TBAs since the TBAs charges were cheap and affordable unlike the charges of the health facility. In addition, the flexibility of their payment method to the TBAs is also more convenient, they were even allowed to pay for the services rendered in instalments to ease their stress and tension. Omollo and colleagues (2016) also reported similar findings. In their studies, they noted that one of the reasons why women were loyal to the utilization of TBAs services was the flexibility in payments in that they were able to pay for TBAs services in kind through foodstuffs such as baking flour, sugar and live chickens.

\section{Conclusion}

Our findings show that most women give birth at home due to several individual, family and health system-related factors including, negative attitude towards facility based delivery services such as perceived poor quality due to harassment by health staffs, lack of equipment, lack of staffs and payment for unavailable items. Moreover, various physical and socioeconomic barriers including long distances, lack of money for transport and payment for services rendered at the health facility prevented women from delivering at the health facilities. These results offer starting points for future interventions which, in our opinion, should focus on improving the staffing and motivation levels for midwives and nurses in the health facilities in the country.

Our findings also revealed that, respondents' had a very positive attitude towards TBA services. This confidence in TBA care is further confirmed by their relatively high use of these services. In view of the perceived vital role of TBAs as seen by these respondents, equipping them with knowledge and skills within accepted standards is therefore necessary. This will ensure that users receive optimum care within their limits of practice. Such partnerships should incorporate supportive supervision and skills to recognize and refer high-risk pregnancies in a timely manner. This will ensure that women who cannot access orthodox maternity services can be guaranteed appropriate, accessible and adequate care in close proximity to their residence.

\section{Study challenges and limitations}

The major limitation of this study was that the findings are only based on the experiences of the women who accepted to participate in the study.

\section{Acknowledgements}

This analysis is part of the first author's thesis to fulfil the requirement for a $\mathrm{PhD}$ in Public Health at the Texila American University Guyana. We thank the Ministry of Health at both the National Government and Mombasa County Government. Special thanks too to the 370 study participants for providing valuable information.

\section{References}

[1]. AMREF (2015). AMREF's Position on the Role and Services of Traditional Birth Attendants, 1-2.

[2]. Bergström S, Goodburn E. (2001). The role of traditional birth attendants in the reduction of maternal mortality. Studies in HSO\&P. 17:85-89.

[3]. Bourbonnais N. (2013). Implementing Free Maternal Health Care in Kenya. Challenges, Strategies, and Recommendations. Kenya National Commission of Human Rights.

[4]. Dietsch E. (2010). The experience of being a traditional midwife: relationships with skilled birth attendants. Rural Remote Health. 10(3):1481.

[5]. Fisher AA, Laing EJ, Stoeckel EJ, Townsend WJ (1998). Handbook for family planning operations research design. 2nd. New York, NY, USA: Population Council; p.36.

[6]. Fotso, J.-C., Ezeh, A. C., \& Essendi, H. (2009). Maternal health in resource-poor urban settings: how does women's autonomy influence the utilization of obstetric care services? Reproductive Health, 6, 9.

[7]. Ikamari, L., Izugbara, C., \& Ochako, R. (2013). Prevalence and determinants of unintended pregnancy among women in Nairobi, Kenya. BMC Pregnancy and Childbirth, 13(1), 69. 
[8]. KDHS. (2014). Kenya demographic and health survey: Key indicators, 1-76.

[9]. Keri, L., Kaye, D., \& Sibylle, K. (2010). Referral practices and perceived barriers to timely obstetric care among Ugandan traditional birth attendants (TBA). African Health Sciences, 10(1), 75-81.

[10]. KNBS, Mombasa. (2009). 2009 Census. Kenya National Bureau of Statistics.

[11]. Mannah, M. T., Warren, C., Kuria, S., \& Adegoke, A. A. (2014). Opportunities and challenges in implementing community based skilled birth attendance strategy in Kenya. BMC Pregnancy and Childbirth, 14(1), 279.

[12]. Mwewa D, Michelo C (2010). Factors associated with home deliveries in a low-income rural settingobservations from Nchelenge District Zambia. Med J Zambia.37(4):234-9.

[13]. Navaneetham K, Dharmalingam A (2006). Utilization of maternal health care services in Southern India. Soc Sci Med. 55:1849-69.

[14]. Nyamtema AS, Urassa DP, Roosmalen JV (2011). Maternal health interventions in resource limited countries: a systematic review of packages, impacts and factors for change. BMC Pregnancy Childbirth. 11:30.

[15]. Omollo J. Vistoria, Oboka W. Aluoch, Janet N. Kassilly (2016). Factors influencing mothers' choice of birth attendants in Bunyala sub- county, Kenya. International Review of Humanities and Scientific Research. 2519-5336

[16]. Shiferaw, S., Spigt, M., Godefrooij, M., Melkamu, Y., \& Tekie, M. (2013). Why do women prefer home births in Ethiopia? BMC Pregnancy Childbirth, 13:2393-13-5.

[17]. Sialubanje C, Massar K, Hamer DH, Ruiter RAC (2014). Psychosocial and environmental predictors of the intention to Use maternal healthcare services in Kalomo, Zambia. Health Educ Res. 29(6):1028-40.

[18]. Stekelenburg J, Kyanamina S, Mukelabai M, Wolffers I, van Roosmalen J (2004). Waiting too long: low use of maternal health services in Kalabo, Zambia. Trop Med Int Health. 390-398.

[19]. Thaddeus S, Maine D (1994). "Too far to walk: maternal mortality in context,". Social Science and Medicine. 38(8):1110.

[20]. Titaley CR, Hunter CL, Dibley MJ, Heywood P (2010). Why do some women still prefer traditional birth attendants and home delivery? A qualitative study on delivery care services in West Java Province, Indonesia. BMC Pregnancy Childbirth. 10:43.

[21]. Vieira, C., Portela, A., Miller, T., Coast, E., Leone, T., \& Marston, C. (2012). Increasing the use of skilled health personnel where traditional birth attendants were providers of childbirth care: A systematic review. PLoS ONE, 7(10), e47946.

[22]. World Health Organisation (2010). Classifying Health Workers. Geneva.

[23]. World Health Organisation (1992). Traditional Birth Attendants: a joint WHO/UNFPA/UNICEF statement. Geneva. 